Vol.- 02, Issue- 01, 2011

\title{
Views of students regarding effective clinical teaching and learning in dental education
}

\author{
Ansary $J A,{ }^{1}$ Ara I, ${ }^{2}$ Talukder HK, ${ }^{3}$ Alam ASMM,${ }^{4}$ Amin $S,{ }^{5}$ Rahman $S M H .{ }^{6}$
}

\begin{abstract}
This study explores the perceptions of students of the features of effective clinical teaching and learning in dental education. This was a qualitative study conducted in one government and one private dental college selected purposively. Study population was final year dental students of selected Dental colleges. A total of 29 students participated in this study. An open ended questionnaire was developed for the focus group discussion for the students. From the students focus group discussion the following seven themes were identified, (1) Organization of the teaching and learning session, (2) stimulating and encouraging teaching and learning session, (3) achieving goal, (4) learning objectives, (5) active participation, (6) scope of frequent brief practice, and (7) feedback. These themes were further subdivided into 26 sub-themes. The features of clinical training experiences that dental students perceived were effective. Our students perceived that authentic clinical experiences are important to their clinical learning, allowing them to see the patient as a whole, be the first medical contact for the patient, and take more responsibility of their own learning and apply patient-centered care. Students also identified the importance of the scope of clinical cases they saw in terms of numbers, variety, offering varied clinical signs and unusual and interesting cases. Our students also felt that their teachers' positive attitudes, ability to establish a good supervisory relationship were important to learning. It has also been shown that students value good feedback in clinical teaching and learning. Our students also felt that the learning environment contributes to their learning.

Study recommended that consideration of increasing time and patient availability in clinical setting could contribute to dental students' effective clinical learning and skills competency.
\end{abstract}

Key Words: Views of students, Effective clinical teaching, Effective clinical learning, dental education.

\section{Rationale of the study}

In dental education context of Bangladesh, clinical teaching and learning has been less extensively examined. The purpose of the study was to find out the students' experiences, views and interpretation of the students' clinical placement experience. These students' perceptions are important because they provide insight into the factors that hinder teaching and learning in clinical practice and can suggest approaches for improvement that can be used in future for curriculum development.

\section{Objective of the study}

To explore dental students' views regarding effective clinical teaching and learning in dental education.

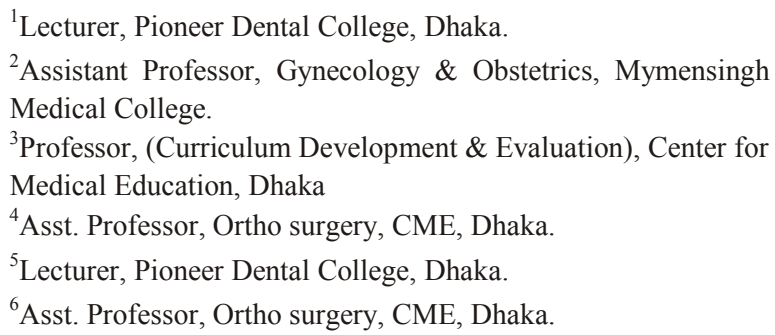

Address of correspondence: Lecturer, Pioneer Dental College, Dhaka.

\section{Materials and Methods}

This was a qualitative Study (cross sectional). It was conducted at one government and one private dental college. Study period was July 2010 to June 2011. Study population where the final year dental students of selected Dental colleges. One government and one non-government dental institute were selected purposively from the list of dental colleges of Dhaka and student's willingly responded after informing them about the study. A total of twentynine students participated in this study. An open ended questionnaire was developed for the focus group discussion of the students. The instrument was developed initially and was finalized after pre-testing out side of the study area. This research was conducted after getting permission from respective authority and verbal consent from all respondents. All respondents participated voluntarily in this study. Confidentiality of the response of the respondents has been maintained.

\section{Introduction}

Dental education is regarded as a complex, demanding and often stressful pedagogical procedure. Undergraduates, while enrolled in programs of 4 years duration, are required to attain a unique and diverse collection of competences. Despite the major differences in educational systems, philosophies, methods and resources available worldwide. ${ }^{1}$ Clinical skills teaching are provided both in ambulatory and inpatient settings. This combination of teaching settings is likely to provide the most effective approach to dental students. 
The clinical learning is affected by many factors, including the varieties of clinical cases encountered, the quality of supervision and feedback, good organization of the experiences and characteristics of learners and teachers. However, the impact of some of these factors on students' clinical learning, when tested, is not always confirmed.

The effectiveness of teaching and learning in the clinical learning environment and how it prepares dental students to independently provide patient care is a central concern in dental education. There is growing awareness that learners' responses to and views of their educational experiences are important in modifying the educational process.

\section{Results}

\section{Student focus group interviews}

Seven main themes were identified for the experiences and activities students felt contributed to their clinical competence: (1) Organization of the teaching and learning session, (2) stimulating and encouraging teaching and learning session, (3) achieving goal, (4) learning objectives, (5) active participation, (6) scope of frequent brief practice, and (7) feedback. The seven main themes are further divided into sub-themes, as shown in Table 1. In the following text, we present these themes along with quotations from students as illustrations.

\section{Theme 1: Organization of the teaching and learning session Curricular factors}

Students perceived that their involvement in the planning process of the teaching policies and activities stimulated them to learn better. Students reported that,

"Opportunity for more clinic time early in the curriculum would be the most beneficial enhancement to our education." (Student Focus Group \#1)

Other curricular factors that students commented on are,

"The curriculum must be delivered in an innovative manner including different methods to suit students with different learning styles and capacities. (Student Focus Group \#4)

\section{Learning environment}

A good clinical learning environment was also perceived as an important factor in learning.

"If the environment is healthy, I learn better. I mean if there is enough time, no rush and the teacher is willing to teach." (Student Focus Group \#2)

"An ideal dental educational environment should enable us to acquire the necessary theoretical, clinical and interpersonal competences and expose them to 'clinical experiences' equivalent to the environment in which we are going to practice dentistry after graduation."

(Student Focus Group \#2)

\section{Number of cases}

Students indicated that exposure to an adequate number of clinical cases during the clinical rotation is important to the development of their clinical skills.

"In conservative department I had chance to practice the root canal procedure several times because a good number of patient was available and I feel confident about the procedure but in pediatric dentistry number of patient with pulp disease was very few and I think I have lack of confidence in pulp therapy procedure of child patient." (Student Focus Group \#1)

Table 1: Themes and sub-themes

\begin{tabular}{|l|l|l|}
\hline Theme 1 & \multicolumn{1}{|c|}{ Theme } & \multicolumn{1}{c|}{ Sub-themes } \\
\hline Theme 2 & $\begin{array}{l}\text { Organization of the teaching and } \\
\text { learning session }\end{array}$ & $\begin{array}{l}\text { Curricular factors Learning environment Preparation and } \\
\text { follow-up activities of the clinical session Knowledgeable } \\
\text { Faculty Number of cases Additional cases }\end{array}$ \\
\hline Theme 3 & $\begin{array}{l}\text { Stimulating and encouraging teaching } \\
\text { and learning session }\end{array}$ & $\begin{array}{l}\text { Integrated experiences Unusual/interesting cases Active } \\
\text { Positive clinical signs Personal learning characteristics } \\
\text { Communication skill Patient-centered care Learning by seeing }\end{array}$ \\
\hline Theme 4 & Achieving goal & $\begin{array}{l}\text { Supervision skills Teacher-student relationship Application of } \\
\text { knowledge Variety of cases }\end{array}$ \\
\hline Theme 5 & learning objectives 6 & $\begin{array}{l}\text { Active participation } \\
\text { learning objectives }\end{array}$ \\
\hline Theme 7 & Scope of frequent brief practice & $\begin{array}{l}\text { Active involvement in patient care First contact experiences } \\
\text { Patient-centered care Learning by seeing }\end{array}$ \\
\hline Theme 8 & Feedback & Time for practice Scope for practice \\
\hline
\end{tabular}


Theme 2: Stimulating and encouraging teaching and learning session Integrated experiences

Students perceived that effective clinical experiences were those that were comprehensive and meaningful to them.

"Seeing patients from $A$ to $Z$ is very beneficial and encouraging. I mean performing all the necessary things for the patient when he presented in the clinic. Starting with greeting him, introducing ourselves, taking history, doing the physical examination, counseling him, and discussing all different issues with the patient. This type of integration really increases our confidence." (Student Focus Group \#2)

"Practice in general clinics allows us to see many patients with varieties of clinical presentations. We are not restricted to a single system or a specialty." (Student Focus Group \#3)

In the classroom, lab, and clinic, students appreciated opportunities to see how the individual pieces they were learning fit into the big picture, to grasp important concepts, to integrate their knowledge, and to cultivate their ability to transfer their learning into real clinical settings. They thought this to be very stimulating and encouraging for their learning.

\section{Unusual/interesting cases}

Students felt they learned better when they found that the clinical case they encountered was stimulating and rare.

"I met a patient who came to the outdoor with dry socket. He was later diagnosed with osteomylitis. It was striking for me and the patient. I learned to be more cautious in certain situations. (Student Focus Group \#2)

\section{Theme 3: Achieving goal Supervision skills}

Students perceived that supervisors should have certain teaching skills to facilitate students' learning in the clinical environment

"Sometimes the clinical supervisor does not have enough experience in providing feedback. They are doing their best, but actually that does not help me a lot to achieve my goals."

(Student Focus Group \#1)

\section{Teacher-student relationship}

Students also felt that a good student-teacher relationship facilitates students' learning and leads them to achieve their learning goals.

"I noticed that when I was attached to an individual consultant, after some time he or she will get better acquainted with me and start to recognize my strengths and weaknesses, thus resulting in a good relationship. This helped me to achieve my goal and made my learning more effective. " (Student Focus Group \#2)

\section{Theme 4: Learning objectives Selection and organizing learning objectives}

Identifying the core parts that the students need to learn and to organize them into a sequential manner is an integral part of a teaching and learning session. The students agreed with the fact that well organized learning objectives are very important for their effective learning.

"In children clinical rotation our instructor came to us and said, 'today I am going to show you how to prepare a access cavity for root canal treatment and how to locate canals and at the end of the session I think you all will be able to do so.' We learnt better in that session."

(Student Focus Group \#3)

\section{Clearly defined learning objectives}

Students mentioned that if the teachers clarify what the session is about and what they are going to learn at the very beginning of a session their learning would have been more effective.

"One of our teachers gives us a list that consists of things that we are going to learn during the session. This helps us to have a clear understanding what our goal is and guide us through the session. I think it is very helpful." ( $\mathrm{S}$ t u d e n t Focus Group \#4)

\section{Theme 5: Active participation Active involvement in patient care}

Active involvement in the patient's care is perceived as factor that stimulates students to learn better in the clinical setting. Staff or consultants may need to encourage students' active involvement, as was mentioned by a student

"I think what really encourages me is the enthusiasm of the consultant to actively involve me, as a medical student in the clinical rotation." (Student Focus Group \#4)

\section{Patient Interactions}

Not surprisingly, the most frequently described positive experience was the opportunity to work with patients. The patient interaction helped dental students increase their confidence when performing new skills. The following direct quotes from dental students illustrate this theme:

"One positive experience was being ableto give comprehensive care to my patients and being involved in every step of the Way-from treatment planning to carrying out treatment." (Student Focus Group \#3)

\section{Theme 6: Scope of frequent brief practice Time for practice}

Most of the students strongly stated their opinion about the fact that the more time they get to practice the more they learn better in clinical setting. Practicing a particular skill for an adequate period of time helps them to gain confidence.

"In first year we had to learn how to mix impression material and take an impression of teeth. We had a lot of time to practice and now we can mix the material without wasting any material and take an impression properly. I think time for practice played an important roll to grow this competence." (Student Focus Group \#2)

\section{Scope for practice}

Students also mentioned that having scope to practice a clinical skill plays a vital roll in effective clinical learning. 
"In our clinical setting most of the patients are dealt by senior trainee doctors. We had nothing to do but to see and learn. We had less opportunity to practice. We can't say anything to them because they are senior. I don't know if I can perform some of the procedures by just seeing them." (Student Focus Group \#4)

\section{Feedback from teacher}

Students recognized that prompt, informative, and sometimescritical feedback was necessary for development of their clinical skills. Effective feedback was timely, which was facilitated by having a number of instructors on the lab or clinic floor. In addition, effective feedback was constructive and specific, leaving the student with a plan for what to do next to achieve the desired result.

"When I first started to open a tooth for root canal treatment my instructor was with me through the whole procedure. He guided me through every step. In every step he told me what to do and what will happen if I do it wrong. His presence and continuous feedback helped me learn the procedure with a clear conception." $\quad$ (Student Focus Group \#3)

\section{Discussion}

This study aimed to explore dental students' views of the types of experiences and activities that contributed to students' clinical competence. Students identified the importance of the scope of clinical cases they saw in terms of numbers, variety, offering varied clinical signs and unusual and interesting cases. Previous studies have demonstrated that clinical volume helps students gain clinical skills ${ }^{2}$ and that it is patient variation found through the volume of clinical experiences that is important. ${ }^{3,4}$ Our students perceived that clinical experiences are important to their clinical learning, allowing them to see the patient as a whole, take more responsibility of their own learning and apply patient-centered care.

These students identified several organizational factors as important to their learning such as curricular factors, feedback from teacher and learning environment. The frequent thought of the students about time spent in the clinical setting is not enough which should be brought to consideration with emphasis.

Our students also felt that the learning environment contributes to their learning. In order to get the best out of anyone, whether a student or a teacher, the working environment has to be optimal. If it is congenial, the end result is definitely going to be better than if the environment were to be stressful or not so congenial. ${ }^{5}$

Supervision appears to be the key to the success of clerkships. In a study supervision was defined as "the provision of monitoring, guidance and feedback on matters of personal, professional and educational development in the context of the doctor's care of patients". 6 Several key characteristics of effective learning experiences were identified in relation to teaching factors in this study.
Instructor personal qualities such as approachability, positive attitudes, commitment, good teaching skills with knowledge and willingness to give guidance and feedback contributed to effective learning experiences and educational development in the context of the doctor's care of patients". It has also been shown that students value good feedback in clinical teaching and learning ${ }^{7}$ and that good feedback directly influences students' performance. By giving feedback and encouraging students to reflect, supervisors can have a positive affect on learning. Others have previously reported that teachers are more effective when they show a positive attitude and enthusiasm for teaching, demonstrate good clinical skills, and practice ethically. ${ }^{8}$

\section{Conclusion}

This study has identified the factors that students and teachers of our dental colleges believe affect clinical learning. These factors can be considered when planning and developing dental curricula, to promote effective clinical rotations and students' learning. It should be noted that this study queried perceptions, and relying on only subjective assessments and personal views and experiences cannot confirm or quantify the impact of each factor identified. Further studies using other, complementary study approaches should assess the impact of the factors identified by the students of this study.

\section{References}

1. Divaris K., Barlow PJ, Chendea SA, Cheong WS, Dounis A, Dragan IF, Hamlin J, Hosseinzadeh L, Kuin D, Mitrirattanakul S, Mo'nes M, Molnar N, Perryer G, Pickup J, Raval N, Shanahan D, Songpaisan Y, Taneva E, Yaghoub-Zadeh S, West K and Vrazic D.(2008). The academic environment: the students' perspective. Eur $J$ Dent Educ 12 (Suppl. 1), 120-130.

2. Rolfe IE, Sanso-Fisher RW. (2002). Translating learning principles into practice: a new strategy for learning clinical skill. Medical Education.; 36(4):345352.

3. Dolmans DH, Wolfhagen HAP, Essed GG, Scherpbier AJ, Vleuten CP. (2002). The impact of supervision, patient mix, and numbers of students on the effectiveness of clinical rotations. Academic Medicine. 77(4):332-335.

4. Chatenay M, Maguire T, Skakum E, Chang G, Cook D, Warnock GL. (1996). Does volume of clinical experience affect Performance of clinical clerks on surgery exit examinations? American Journal of Surgery. 172(4):366-372. 20.

5. Betsy ST, Reem RA, Mohan A \& Ramnarayan K. (2009). Students' perceptions regarding educational environment in an Indian dental school. Medical Teacher; 31: e185-e188 
6. Kilminster, S.M., \& Jolly, B.C. (2000) Effective supervision in clinical practice settings: a literature review. Medical Education, 34, 827-840.

7. Lawrence SL, Lindemann JC, Gottlieb M. (1999). What students' value: learning outcomes in a required third-year ambulatory primary care clerkship. Academic Medicine; 74(6):715-717.

8. Buchel TL, Edwards FD. (2005). Characteristics of effective clinical teachers. Family Medicine. 2005; 37(1): 30-35. 